\title{
A Metafísica na Philosophica
}

\author{
Vasco Baptista Marques ${ }^{1}$
}

(Centro de Filosofia da Universidade de Lisboa)

A pretex to da publicação do quinquagésimo número da Philosophica, entregamo-nos a um trabalho ciclópico, nomeadamente: o de recensearmos os artigos de metafísica que, nos últimos vinte e cinco anos (19932017), encontraram lugar nas páginas da revista ${ }^{2}$. Estamos em face de uma tarefa que, preliminarmente, nos obriga a determinar o sentido do conceito de metafísica do qual aqui faremos uso. Digamo-lo desde já: na presente recensão, a expressão "metafísica" será entendida, não em sentido fechado ou de um ponto de vista técnico, mas em sentido aberto ou de um ponto de vista histórico. O que significa isto? Significa, em substância, que a sua utilização não implica a subscrição de qualquer uma das múltiplas e particulares definições de metafísica que nos foram legadas pela tradição - por exemplo: aquela, de matriz aristotélica, que a circunscreve como a ciência do ente enquanto ente ( $\tau$ ò ôv $\tilde{\eta}$ ôv $)^{3}$-, mas, bem pelo contrário, a possibilidade de as acolhermos a todas, para darmos notícia das diferentes configurações que o conceito em apreço foi assumindo, ao longo da sua evolução histórica. O propósito que comanda a indeterminação semântica do termo

\footnotetext{
1 vascobmarques@hotmail.com

2 De um universo de quatrocentos e quarenta e quatro artigos publicados até à data na Philosophica, cento e trinta foram aqueles que escolheram debruçar-se sobre problemas de metafísica, o que significa que a referida disciplina cativou a atenção de $29,3 \%$ da produção científica vertida na revista.

3 Cf. Aristóteles, Metafísica, III, 1, 1003a21 e V, 1, $1026 \mathrm{a} 31$.
}

Philosophica, 50, Lisboa, 2017, pp. 53-65. 
"metafísica" é simples: o de colocarmos em evidência a viabilidade de reconstituirmos uma história da metafísica, a partir do conjunto de artigos que, a respeito de tópicos dessa mesma disciplina, foram divulgados pela Philosophica. De modo a fazê-lo, cuidaremos de seguir uma ordem de exposição cronológica, que seja capaz de revelar a atenção que na revista foi dedicada às quatro grandes épocas da história da metafísica: a antiga, a medieval, a moderna e a contemporânea ${ }^{4}$. Comecemos, pois, por onde o Timeu de Platão nos adverte que é indispensável começar em qualquer matéria - a saber, pelo começo ${ }^{5}$-, e vejamos em que moldes foram as metafísicas dos antigos trabalhadas neste contexto.

\section{1 - A metafísica antiga}

O percurso pela história da metafísica que a Philosophica nos convida a empreender tem, na nossa óptica, um ponto de partida incontornável: o artigo de carácter panorâmico onde Tina Röck se propõe auscultar o(s) sentido(s) do conceito grego de natureza $(f \varphi v ́ \sigma ı)^{6}$. Nele, a autora começa por elencar a miríade de sentidos equívocos que os antigos estavam atribuindo à expressão em causa, para, posteriormente, interrogar pela natureza do vínculo que os unifica. A hipótese de resposta então forjada, essa, sugere que o termo " $\varphi v ́ \sigma ı \varsigma$ ” foi empregue pelos primeiros filósofos pré-socráticos para significar o ser em si mesmo considerado. Ou, se preferirmos: para referir a propriedade fundamental (a de ser) que nos permite religar todas as coisas entre si.

Dando continuidade ao trajecto assim iniciado, Pedro Braga Falcão e António Pedro Mesquita conduzir-nos-ão até à filosofia de Heraclito, para respectivamente sondarem 1) os exactos contornos do sujeito que, nos seus fragmentos, é nomeado pela locução "o deus" (“ó $\theta \varepsilon o ́ \varsigma$ ”) ${ }^{7}$ e; 2)

4 Deixamos à partida de lado o recenseamento dos artigos de metafísica publicados nos números monográficos da Philosophica, assim como aqueles que versam sobre o pensamento metafísico de autores portugueses, na medida em que os mesmos constituirão o objecto de estudos autónomos.

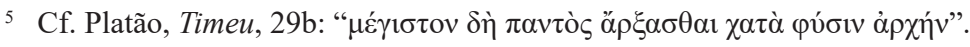

6 Tina Röck, "The concept of nature - from pre-socratic physis to the natural кó $\sigma \mu$ os of the Timaeus", Philosophica, 47 (Lisboa, 2016), pp. 9-26.

7 Pedro Braga Falcão, “O ‘deus’ em Heraclito ou dos deuses ao deus”, Philosophica, 23 (Lisboa, 2004), pp. 53-67. 
a concepção de filosofia que o seu pensamento implicitamente está veiculando ${ }^{8}$. Trata-se, neste último caso, de analisar as passagens do Efésio onde a expressão " $\varphi \imath \lambda i ́ \alpha$ " ocorre, para expor a sua filosofia como o lugar da primeira formulação histórica de uma clara distinção entre a realidade e a aparência - distinção essa que, por sua vez, permitiu a Heraclito tematizar a filosofia como uma via de acesso privilegiada ao real.

É ainda pela mão de António Pedro Mesquita que entramos no platonismo, com um texto bicéfalo onde, primeiro, se advoga que a demonstração da imortalidade da alma realizada no Fédon não representa uma versão primitiva do argumento ontológico ${ }^{9}$, e onde, depois, se sustenta que o argumento ontológico configura a estrutura de fundo que insensivelmente regula a totalidade da metafísica platónica ${ }^{10}$. Em complemento a este trabalho, António Pedro Mesquita oferece-nos também um estudo

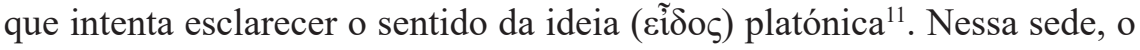
autor suporta - contra a maioria dos intérpretes da filosofia de Platão - a tese de que, longe de infirmar a teoria das ideias alinhavada no Fédon, o Parménides conforma, antes, o momento em que a mesma acede à sua plena demonstração, e, por conseguinte, o momento em que a noção de ideia é cabalmente clarificada quanto ao seu significado (significado esse que, segundo António Pedro Mesquita, impossibilita a tradução corrente

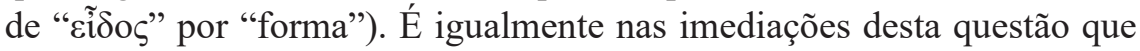
se move o artigo que José Trindade Santos consagrou à escalpelização da metafísica platónica ${ }^{12}$, e no qual começa justamente por perguntar se o Parménides pode ser entendido como o quadro do anúncio da revisão - ou, até, do abandono - da teoria das formas. De maneira a responder a esta interrogação, o estudo concentrará o seu olhar sobre um tópico platónico não muito estudado, designadamente: o da teoria e prática dos paradigmas $(\pi \alpha \rho \alpha \delta \varepsilon i ́ \gamma \mu \alpha \tau \alpha)$ desenvolvida no Político, que será aqui confrontada com as concepções platónicas acerca da linguagem.

\footnotetext{
8 António Pedro Mesquita, " $\lambda o ́ \gamma o \varsigma$ e $\varphi \imath \lambda i ́ \alpha$ em Heraclito. Sentido e função do conceito de pı $\lambda$ ía em Heraclito", Philosophica, 13 (Lisboa, 1999), pp. 13-42.

9 António Pedro Mesquita, "O argumento ontológico em Platão: (I) o problema da imortalidade”, Philosophica, 2 (Lisboa, 1993), pp. 31-42.

10 António Pedro Mesquita, "O argumento ontológico em Platão: (II) a imortalidade do problema", Philosophica, 3 (Lisboa, 1994), pp. 85-109.

11 António Pedro Mesquita, “A natureza da ideia platónica. A propósito de duas passagenschave: Fédon 83b, Parménides 141e-142",, Philosophica, 10 (Lisboa, 1997), pp. 45-76.

12 José Trindade Santos, "Platão, Heraclito e a estrutura metafórica do real", Philosophica, 1 (Lisboa, 1993), pp. 45-68.
} 
O lugar da formulação e da elucidação do problema que, do nosso ponto de vista, constitui o nó górdio da metafísica clássica, é o ensaio que António Pedro Mesquita votou ao estudo comparado dos conceitos platónico e aristotélico de substância (ov̉ бía) ${ }^{13}$. Motivado pela vontade de pôr a nu a diferença essencial existente entre as ontologias dos dois autores, o artigo defende que a irredutível especificidade da última reside no modo como - reagindo contra o platonismo - levou a cabo a restrição do campo referencial do conceito de substância, vinculando-o a um domínio bem definido de entes: o dos indivíduos, considerados então como sujeitos de predicados. Por forma a provar que assim é, António Pedro Mesquita partirá da tradução e da interpretação da célebre passagem da Metafísica (VII, 1028a10-1028b2) em que, afirmando embora que o ente pode ser dito de muitas maneiras (tantas quantas as categorias que podem subsumi-lo), Aristóteles afirma também que é por via da categoria de substância que ele se deixa tematizar enquanto tal. Uma vez posto isto, o texto empreenderá uma complexa tarefa: a de mostrar como, na ontologia aristotélica, a categoria de substância exprime invariavelmente o ente como um indivíduo de um género determinado. Ou, o que vem a ser o mesmo, como um subs-


Eĩval), por exemplo: a de ser uma mesa, um quadro... Ora, é precisamente essa indissolúvel concreção individuada de substrato e essência que, na Metafísica, está sendo expressa por meio do termo "substância". Caso bem diverso é o da ontologia platónica, no âmbito da qual "substância" nomeia indiferentemente tudo o que em sentido próprio é, leia-se: todas as ideias (a da mesa como a do belo, a do quadro como a do justo...). O que implica isto? Implica que a distinção lavrada por Aristóteles entre a substância e os acidentes, o sujeito e os predicados, nunca poderia ter sido subscrita por Platão, que - excepção feita às coisas sensíveis, derivadas das ideias inteligíveis que conformam a sua matriz - tudo está encarando como uma substância. $\mathrm{O}$ artigo que nos ocupou no decurso das últimas linhas está longe de ter sido o único a aventurar-se pela ontologia aristotélica, que por mais seis vezes foi chamada a comparecer nas páginas da Philosophica. E, desde logo, pelo próprio António Pedro Mesquita, que, para além de uma trilogia de textos respeitantes às questões correlativas da diferença, do acidente e

13 António Pedro Mesquita, "Platão e Aristóteles. Duas teses sobre a substância e as categorias", Philosophica, 7 (Lisboa, 1996), pp. 85-103. 
da predicação ${ }^{14}$, nos apresentou ainda um estudo que averigua o sentido que o Estagirita atribui à locução "se isso é" (" $\varepsilon i$ č $\sigma \tau \imath v ")$, no Livro II dos Analíticos posteriores ${ }^{15}$. Por seu turno, Pedro Braga Falcão investiga se a

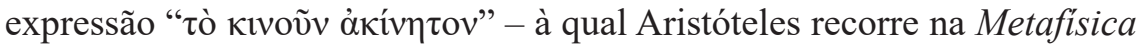
- pode ser adequadamente vertida para português por "o motor imóvel", perguntando, ademais, se o referente dessa frase consente ser identificado, sem mais, com o Deus aristotélico ${ }^{16}$. Encerrando o nosso percurso pela metafísica antiga, Lucas Díaz López analisa as putativas incoerências lógicas do Organon, relacionando-as com a ontologia aristotélica ${ }^{17}$.

\section{2 - A metafísica tardo-antiga e medieval}

Embora escassos quanto ao número, os sete artigos publicados na Philosophica que se debruçaram sobre as metafísicas tardo-antigas e medievais desenham um itinerário compreensivo, que vai do neoplatonismo ao Renascimento, passando pela escolástica e pela mística renana. É efectivamente no centro das preocupações neoplatónicas que nos implanta o ensaio que Paulo A. Borges dedicou ao estudo do uno plotiniano ${ }^{18}$. Aos problemas do pensamento escolástico se dirige, por seu lado, o texto em que Maria Leonor Xavier procura evidenciar as afinidades entre as metafísicas de Anselmo e Duns Escoto ${ }^{19}$, que, de acordo com a autora, se deixam articular em função da sua comum adesão a uma mesma série de princípios. De entre eles, Maria Leonor Xavier cuidará de destacar o princípio (agostiniano) da irreflexividade da relação ou do processo de geração, que determina a impossibilidade da auto-geração na esfera das coisas existentes. $\mathrm{Na}$

14 António Pedro Mesquita, "O estatuto predicativo das diferenças em Aristóteles", Philosophica, 16 (Lisboa, 2000), pp. 3-46; "O problema da definição do acidente em Aristóteles", Philosophica, 17-18 (Lisboa, 2001), pp. 103-149; “Tipos de predicação em Aristóteles: um ensaio de sistematização", Philosophica, 26 (Lisboa, 2005), pp. 7-34.

15 António Pedro Mesquita, "Ei estin. Hipóteses de existência em Aristóteles", Philosophica, 30 (Lisboa, 2007), pp. 141-181).

16 Pedro Braga Falcão, “Movens immobile e 'o Deus' no Livro $\Lambda$ da Metafísica de Aristóteles”, Philosophica, 26 (Lisboa, 2005), pp. 81-97.

17 Lucas Díaz López, "El uso aristotélico de variables en lógica y sus supuestos ontológicos", Philosophica, 38 (Lisboa, 2011), pp. 33-56.

18 Paulo A. Borges, "O desejo e a experiência do uno em Plotino", Philosophica, 26 (Lisboa, 2005), pp. 175-214.

19 Maria Leonor Xavier, “Anselmo e Duns Escoto. Variações sobre um mesmo princípio metafísico”, Philosophica, 31 (Lisboa, 2008), pp. 77-90. 
órbita da filosofia de Anselmo gravita um outro artigo: aquele em que Maria Leonor Xavier examina a recepção da prova anselmiana da existência de Deus por parte de Karl Barth, revelando como, no seu desejo de a reduzir à teologia, o autor perfilha ainda um conjunto de pressupostos filosóficos ${ }^{20}$. Por sua vez, a metafísica de expressão árabe será interpelada por intermédio do escrito que Catarina Belo votou à exposição das raízes aristotélicas do pensamento de Averróis ${ }^{21}$. Afirma-se então que o abandono da teoria da emanação nos textos de maturidade do filósofo árabe foi comandado, em primeira instância, pela necessidade de demonstrar a viabilidade de uma conciliação teórica entre a filosofia islâmica e a filosofia aristotélica. Pelos caminhos da mística renana se adentra o artigo em que Paulo A. Borges inspecciona o significado de um dos mais célebres sermões de Mestre Eckhart ${ }^{22}$. Argumenta-se aí que, em conformidade com Mestre Eckhart, a realização da pobreza em espírito sanciona um acto de autodesapropriação, isto é: um gesto de renúncia à vontade, ao saber e à posse, que, libertando o sujeito de si mesmo, o liberta igualmente de Deus (Gott), permitindo-lhe assim religar-se à divindade (Gottheit) ou ao absolutamente indiferenciado. Lançando uma ponte entre a Idade Média e a Idade Moderna, Mafalda Faria Blanc instalar-nos-á no interior do Renascimento, por meio de um estudo sobre a metafísica de Nicolau de Cusa ${ }^{23}$. Nesse contexto, a análise de $A$ visão de Deus servirá de ponto de partida para a construção de uma leitura panorâmica da teorese do absoluto desenvolvida pelo Cusano, ao longo da qual se concederá a maior atenção à maneira como ela convida $\mathrm{o}$ pensamento humano a mover-se incessantemente entre o sensível e o inteligível. É também no encalço da filosofia de Nicolau de Cusa que segue o último dos artigos que aqui traremos à colação, nomeadamente: aquele onde João Maria André interroga o conceito de Homem como imagem de Deus e microcosmo cunhado pelo Cusano, confrontando-o ulteriormente com o pensamento antropológico de Ficino ${ }^{24}$.

20 Maria Leonor Xavier, “A prova anselmiana segundo Karl Barth”, Philosophica, 5 (Lisboa, 1995), pp. 103-121.

21 Catarina Belo, "O aristotelismo de Averróis e o problema da emanação", Philosophica, 26 (Lisboa, 2005), pp. 215-228.

22 Paulo A. Borges, "Ser ateu graças a Deus ou de como ser pobre é não haver menos que o infinito. A-teísmo, a-teologia, e an-arquia mística no sermão 'Beati pauperes spiritu...' de Mestre Eckhart”, Philosophica, 21 (Lisboa, 2003), pp. 61-77.

23 Mafalda Faria Blanc, "A construção da visão em Nicolau de Cusa", Philosophica, 14 (Lisboa, 1999), pp. 31-49.

24 João Maria André, "O homem como microcosmo. Da concepção dinâmica do homem em Nicolau de Cusa à inflexão espiritualista da antropologia de Ficino", Philosophica, 14 (Lisboa, 1999), pp. 7-30. 


\section{3 - A metafísica moderna}

Os primeiros passos dados pela Philosophica na metafísica moderna inscrevem-se num ensaio de Mafalda Faria Blanc sobre Malebranche ${ }^{25}$. Lidamos com um artigo que chama a si o encargo de contextualizar historicamente a filosofia do autor, situando-a na encruzilhada do racionalismo cartesiano e das teologias medievais, e detectando na sua concepção de metafísica como teologia racional o seu principal traço distintivo. Nele, ver-se-á ainda como o pensamento de Malebranche engendra uma teoria da acção que, segundo Mafalda Faria Blanc, abriu caminho para o surgimento daquelas que, na contemporaneidade, foram forjadas pelas filosofias do espírito de expressão francesa (em particular, as de Ravaisson, Blondel e Lavelle). Até à metafísica leibniziana nos conduz Samuel Dimas, num texto onde se mostra como o autor da Monadologia procurou compatibilizar a liberdade da lei divina com a liberdade da acção humana, distinguindo para o efeito entre a vontade antecedente e a vontade consequente de Deus (que consente a existência do mal e do sofrimento ${ }^{26}$. Quanto aos argumentos que estão concorrendo para a configuração do imaterialismo de Berkeley, esses, foram apresentados e discutidos por Pedro Alves, num artigo que expõe o carácter infundado de uma das mais célebres teses aventadas pelo autor $^{27}$. Mais precisamente: aquela de acordo com a qual um mundo desprovido de matéria e um mundo dela provido seriam indiscerníveis entre si, no que concerne o conteúdo das percepções e a mecânica newtoniana. Reatando laços com a vexata quaestio da metafísica clássica - a da substância -, Maria Luísa Ribeiro Ferreira sopesa os ataques dirigidos pelo empirismo de Hume contra o substancialismo de Espinosa ${ }^{28}$. A posição que nesse quadro se sustenta é a seguinte: a de que o trabalho crítico levado a cabo por Hume passa ao lado do seu objecto, ao distorcer a noção de substância de Espinosa (à qual parece ter acedido sobretudo por via da mediação de Pierre Bayle).

25 Mafalda Faria Blanc, “Apresentação da metafísica de Malebranche”, Philosophica, 1 (Lisboa, 1993), pp. 69-87.

26 Samuel Dimas, "A presença do trágico na teodiceia de Leibniz: a predestinação da salvação eterna e a destinação da condenação eterna", Philosophica, 43 (Lisboa, 2014), pp. 39-58.

27 Pedro Alves, “A proposta(i)modesta de Berkeley: um mundo sem matéria”, Philosophica, 38 (Lisboa, 2011), pp. 59-73.

28 Maria Luísa Ribeiro Ferreira, “A crítica de Hume a Espinosa a propósito da noção de substância”, Philosophica, 24 (Lisboa, 2004), pp. 93-118. 
Punctum crucis da história da modernidade, a ontologia kantiana encontrou eco em dois artigos publicados na Philosophica. O primeiro, da responsabilidade de Pedro Viegas, demonstra como o recorte dado por Kant ao problema da existência num dos seus escritos pré-críticos - no caso, a Nova dilucidatio - aponta já no sentido de uma superação das ontologias racionalistas precedentes ${ }^{29}$. O segundo, da responsabilidade de Pedro Alves, concentra-se sobre as críticas desferidas por Beck contra o conceito kantiano da coisa-em-si (Ding an sich), por forma a ponderar a função por ele desempenhada na economia do empreendimento crítico kantiano $^{30}$. Que o mesmo é dizer: por forma a averiguar se a sua afirmação está sendo organicamente reivindicada pela estrutura interna da faculdade de conhecer, ou se, pelo contrário, ela trai uma concessão ao dogmatismo.

Se houve um capítulo da história da metafísica que mereceu um olhar especialmente atento da parte dos colaboradores da Philosophica, ele foi, sem dúvida, aquele que diz respeito ao idealismo alemão. Nada mais nada menos do que dez foram os artigos que, nas páginas da revista, se debruçaram sobre essa corrente de pensamento, vincando amiúde a maneira como - nos seus múltiplos avatares - ela se constituiu em diálogo crítico com a herança legada pela filosofia de Kant. Prova disso é o ensaio que Manuel J. do Carmo Ferreira dedicou ao estudo do documento fundador do movimento: Das älteste Systemprogramm des deutschen Idealismus ${ }^{31}$. Nesse texto escrito a três mãos (as de Hegel, Hölderlin e Schelling), Manuel J. do Carmo Ferreira está surpreendendo o desejo de ab-rogar o conjunto de aporias suscitadas por um problema especificamente kantiano - o da síntese -, patenteando como o tratamento dialéctico que nesse contexto the foi dado prepara já o terreno para as posteriores reflexões dos seus três autores. Semelhante programa de trabalhos é aquele que nos propõe Fernando Manuel Ferreira da Silva, num artigo que evidencia como Hegel, Hölderlin e Schelling se posicionaram em relação à filosofia kantiana da religião e à sua concepção da providência divina ${ }^{32}$. De entre os ensaios que estão encontrando no idealismo alemão o seu epicentro temático, são em número de seis aqueles que escolheram focar-se, exclusiva ou primordialmente,

29 Pedro Viegas, "O tema da existência na Nova dilucidatio de Kant", Philosophica, 3 (Lisboa, 1994), pp. 111-127.

30 Pedro Alves, "Kant e Beck face ao problema da Coisa-em-si", Philosophica, 2 (Lisboa, 1993), pp. 53-81.

31 Manuel J. do Carmo Ferreira, “A questão da síntese na génese do idealismo alemão, partindo do seu mais antigo programa”, Philosophica, 11 (Lisboa, 1998), pp. 87-109.

32 Fernando Manuel Ferreira Da Silva, "Das Gespräch zwischen Hölderlin, Hegel und Schelling über Kants Antinomien”, Philosophica, 39 (Lisboa, 2012), pp. 55-67. 
na filosofia hegeliana. E, desde logo, aquele em que Félix Duque nos devolve a um período capital no desenvolvimento do jovem Hegel (Iena, 1801-1803), para destacar o modo como a leitura alegórica que o autor então fez do mito de Orestes lhe permitiu lançar os fundamentos teóricos do Estado moderno ${ }^{33}$. Por sua vez, a Fenomenologia do espírito magnetizou o interesse de dois artigos, assinados por Gérard Bensussan e Mafalda Faria Blanc ${ }^{34}$. No primeiro, a de-separação é determinada como o núcleo mesmo da dialéctica especulativa hegeliana, onde - diz-se - a contradição é investida do encargo de promover o restabelecimento da identidade. No segundo, demarcam-se os contornos do conceito de "facto filosófico", contrastando-se para isso aquilo que o próprio Hegel designa como o "trabalho do conceito" com o intuicionismo romântico e o formalismo metodológico da filosofias das Luzes. Por fim, Mafalda Faria Blanc cuidará de definir a natureza do projecto fenomenológico abraçado por Hegel na obra em causa, circunscrevendo-o então como uma propedêutica ao "Sistema da Ciência". A interpretação que Hegel realiza da metafísica de Espinosa será, por seu turno, o objecto de um artigo escrito por João Emiliano Fortaleza de Aquino ${ }^{35}$. Nesse âmbito se mostra que, em conformidade com Hegel, o autor da Ética se revela incapaz de fundamentar a diferença e a singularidade autoconsciente, ao dissolver de forma adialéctica os modos (finitos) na substância (infinita). Na mesma linha se move o ensaio onde Mafalda Blanc analisa as críticas produzidas por Hegel contra as metafísicas de Espinosa e Leibniz, salientando como o primeiro está descortinando nas últimas a postulação de princípios - historicamente necessários, mas invariavelmente unilaterais - da totalidade (Espinosa) e da individualidade $(\text { Leibniz })^{36}$. Quanto ao estudo que José Barata Moura consagrou à ontologia hegeliana ${ }^{37}$, esse, confronta-se de entrada com uma questão de fundo, interrogando: qual é, afinal, a compreensão hegeliana do ser? Estamos em presença de uma pergunta que, tal como o autor bem vincará, só poderá

33 Félix Duque, “'Destrucción de lo divino'. La tragedia del absoluto en el Hegel de Jena", Philosophica, 11 (Lisboa, 1998), pp. 3-22.

34 Gérard Bensussan, "La dé-séparation comme autoproduction du sens: une lecture de la préface de la Phénomènologie de l'esprit", Philosophica, 43 (Lisboa, 2014), pp. 77-97; Mafalda Faria Blanc, "A natureza do filosofar segundo a Fenomenologia do espírito de Hegel”, Philosophica, 13 (Lisboa, 1999), pp. 43-56.

35 João Emiliano Fortaleza De Aquino, "Diferença e singularidade: notas sobre a crítica de Hegel a Spinoza”, Philosophica, 28 (Lisboa, 2006), pp. 109-133.

36 Mafalda Faria Blanc, “A leitura hegeliana de Espinoza e de Leibniz", Philosophica, 8 (Lisboa, 1996), pp. 95-110.

37 José Barata Moura, "Hegel e a ontologia”, Philosophica, 39 (Lisboa, 2012), pp. 7-44. 
ser adequadamente respondida por intermédio da rigorosa distinção de três noções correlativas: as de "ontologia" (Ontologie), de "ser" (Sein) e de "aquilo que é" (das, was ist). Com esse trabalho de destrinça se ocupará preliminarmente um artigo que, em derradeira instância, pretende determinar a ontologia hegeliana como uma "ciência do móvel". Ou melhor: como o saber de um ser que nada tem de fixo, na medida em que ele se põe como o resultado do processo histórico-dialéctico de mediação e de alteração que, continuadamente, o conduz do "ser-em-si" (Ansichsein) ao "ser-outro" (Anderssein). Do lado de Schelling nos coloca um texto onde Xavier Tilliette escalpeliza um escrito datado dos anos de juventude do autor alemão: aquele que serviu de base ao curso de inverno que o mesmo ministrou em Iena, em $1798^{38}$. Dele, Xavier Tilliette releverá a abordagem que o jovem Schelling está fazendo às questões antropológicas (tematizadas em consonância com as directrizes da sua filosofia da natureza) e, em especial, às questões sobre a sexualidade. Por último, e concluindo o trajecto da Philosophica pela metafísica moderna, Cristina Beckert auscultará o conceito de "retorno natal" cunhado por Hölderlin, examinando para isso, não somente os seus poemas, mas também os fragmentos que o autor nos deixou sobre a tragédia grega ${ }^{39}$.

\section{4 - A metafísica contemporânea}

Sabêmo-lo: no seu anseio de justificar a totalidade do processo histórico, o projecto idealista implicou - por uma espécie de efeito de ricochete - o esgotamento da razão metafísica, convidando as filosofias posteriores a abraçar aquilo a que se convencionou chamar um "discurso pós-metafísico". Uma das primeiras a perfilhá-lo foi, sem dúvida, a filosofia do trágico de Nietzsche, que, como sublinha Leonel Ribeiro dos Santos ${ }^{40}$, se encontra marcada na sua génese - entenda-se: nas páginas de A origem da tragédia - pela sua vontade de consumar um movimento especulativo em curso desde Kant. Designadamente: aquele que prescreve a necessidade de um regresso às fontes mitológicas da razão, e que define a arte, não só como o lugar da expressão suprema da subjectividade, do espírito (Gemüt) e da

38 Xavier Tilliette, "Ciência natural e antropologia no jovem Schelling”, Philosophica, 13 (Lisboa, 1999), pp. 3-12.

39 Cristina Beckert, "Hölderlin e o 'retorno natal"”, Philosophica, 3 (Lisboa, 1994), pp. 37-50.

40 Leonel Ribeiro Dos Santos, "O retorno ao mito. Nietzsche, a música e a tragédia", Philosophica, 1 (Lisboa, 1993), pp. 89-111. 
vontade, mas igualmente como o lugar da revelação mesma do absoluto, do ser e da natureza. Prova da contemporaneidade de Nietzsche é, também, o artigo onde Manuel João Pires parte da interpretação de um episódio da biografia do autor alemão, para - em linha com ele - reflectir sobre a viabilidade de uma justificação estética da existência, no quadro de um mundo pós-metafísico ${ }^{41}$. Por seu lado, Vânia Dutra de Azeredo pondera as considerações tecidas por David Harvey acerca da condição pós-moderna, colocando-as em relação com o pensamento nietzscheano ${ }^{42}$.

Obrigando o percurso da Philosophica pela contemporaneidade a inflectir na direcção da filosofia da acção em língua francesa, M. Patrão Neves mergulhar-nos-á no interior da produção de Blondel, com um estudo que demonstra como a sua obra se deixa reger por uma estrutura triádica, determinada pelo vínculo indissociável que ela estabelece entre o pensamento, o ser e a acção ${ }^{43}$. De maneira a fazê-lo, M. Patrão Neves tratará primeiro de retraçar o itinerário reflexivo que vai de L'action à Trilogia, para, numa segunda fase, tomar em conta os aspectos que tornam possível patentear a existência de uma estrutura triádica na filosofia da acção de Blondel, nomeadamente: o sentido da acção como mediação, a dialéctica da acção e a lógica da acção.

Momento capital da história da contemporaneidade, a ontologia fenomenológica constitui o objecto de cinco dos artigos que, até à data, foram publicados na revista. Entre a maioria deles, julgamos estar detectando um denominador comum: o desejo de exibir como, nas suas múltiplas declinações, a ontologia fenomenológica retomou e repensou alguns dos principais problemas da metafísica clássica. Exemplo cabal disso mesmo é, do nosso ponto de vista, o ensaio em que Pedro Alves se propõe estudar a forma como Husserl se apropria da ideia aristotélica de algo como uma

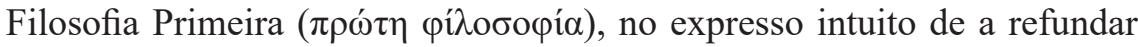
quanto ao seu sentido e aos seus limites ${ }^{44}$. Começando por demarcar a intencionalidade da consciência como o tema fundamental da fenomenologia husserliana, Pedro Alves evidenciará que a escolha desse tema configura, para o autor das Ideen, o único modo de dar resposta adequada a

${ }_{41}$ Manuel João Pires, "Nietzsche e o cavalo. Prelúdio a uma justificação estética da existência”, Philosophica, 16 (Lisboa, 2000), pp. 117-134.

42 Vânia Dutra De Azeredo, "David Harvey e Friedrich Nietzsche: pós-modernidade ou extemporaneidade", Philosophica, 39 (Lisboa, 2012), pp. 69-95.

43 M. Patrão Neves, "A estrutura triádica da filosofia de M. Blondel (o trinitarismo blondeliano)", Philosophica, 11 (Lisboa, 1997), pp. 23-38.

44 Pedro Alves, "A ideia de uma Filosofia Primeira na fenomenologia de Edmund Husserl. Uma tentativa de interpretação", Philosophica, 7 (Lisboa, 1996), pp. 3-37. 
uma pergunta basilar: aquela que diz respeito à possibilidade de edificar, não uma simples psicologia, mas uma ciência primeira e universal que, fazendo jus ao seu nome, venha a debruçar-se sobre a totalidade daquilo que é. Prosseguindo no domínio da fenomenologia, Mafalda Faria Blanc procurará recompor as grandes etapas da aventura filosófica que, em 1927 - e no decurso de Ser e tempo -, levou Heidegger a reavaliar historicamente a questão do ser e a assumir um projecto de reforma da metafísica enquanto ciência ${ }^{45}$. Cuidar-se-á, neste contexto, de apresentar o conjunto de "influências" que contribuíram para a leitura realizada por Heidegger em Ser e tempo (desde a metafísica aristotélica até às filosofias existencialistas, passando pela escolástica e o neokantismo...), mostrando como - com elas ou contra elas - Heidegger chamou a si a missão de desenvolver uma nova concepção do ser a partir do tempo. Em estreita articulação com este artigo, está aquele em que Mafalda Faria Blanc revisita o programa heideggeriano de desconstrução da história da metafísica, contrastando-o criticamente com a ideia de desconstrução alinhavada por Derrida ${ }^{46}$. Por sua vez, Manuel Peixe Dias reimplanta-nos no Encontro de Davos de 1929, para invocar e equacionar as traves mestras do debate que, então, opôs Cassirer a Heidegger ${ }^{47}$. Nele, o autor julga estar surpreendendo os primeiros sintomas da querela da modernidade e da pós-modernidade. Ao texto de Fabio Samuel Esquenazi sobre a filosofia de Levinas ${ }^{48}$ cabe a honra de encerrar a odisseia da Philosophica pela história da metafísica contemporânea. O seu fito? O de enunciar e problematizar os argumentos que estão dando razão do distanciamento de Levinas em relação ao pensamento místico e religioso.

Não seria justo concluir a presente recensão, sem dirigirmos pelo menos uma palavra à série de estudos temáticos e/ou originais sobre tópicos de metafísica que, ao longo dos últimos vinte e cinco anos, foram encontrando espaço nas páginas da Philosophica. Falamos aqui, a título de exemplo, daquele que Carlos João Correia votou à distinção dos conceitos de religião e de Deus ${ }^{49}$; daquele em que Markus Gabriel analisa o nexo

45 Mafalda Faria Blanc, "O problema da metafísica em Heidegger no período de gestação de Ser e tempo", Philosophica, 43 (Lisboa, 2014), pp. 99-114.

46 Mafalda Faria Blanc, "Desconstrução e retomação. Heidegger e a demanda do originário", Philosophica, 45 (Lisboa, 2015), pp. 57-68.

47 Manuel Peixe Dias, “Cassirer/Heidegger. O encontro de Davos ou o debate sobre Kant e a modernidade", Philosophica, 10 (Lisboa, 1997), pp. 121-134.

48 Fabio Samuel Esquenazi, "Le refus lévinassien de la mystique. Raisons et observations", Philosophica, 45 (Lisboa, 2015), pp. 69-81.

49 Carlos João Correia, “A religião e a experiência do divino”, Philosophica, 17-18 (Lisboa, 2001), pp. 49-59. 
existente entre as noções de ontonomia e teonomia ${ }^{50}$; daquele que Mafalda Faria Blanc dedicou à investigação das fontes intuitivas e ontológicas da razã $0^{51}$; e daquele em que José Barata Moura procede à elencagem dos vários avatares históricos do problema da acção - acompanhando a sua peregrinação desde a antiguidade até à contemporaneidade -, para, num segundo momento, indicar as possíveis vias para a constituição de algo como uma ontologia da acção $0^{52}$. É prova de que, na Philosophica, a recuperação da história da metafísica caminhou sempre de mãos dadas com a sua reinvenção.

50 Markus Gabriel, "Metafísica e mitologia”, Philosophica, 27 (Lisboa, 2006), pp. 53-67.

51 Mafalda Faria Blanc, "Luz da Razão. Para uma fundamentação onto-metafísica", Philosophica, 33 (Lisboa, 2009), pp. 7-18.

52 José Barata-Moura, "Prolegómenos a uma ontologia da acção", Philosophica, 3 (Lisboa, 1993), pp. 51-70. 